\title{
Bromelain vs Papain Gel for Caries Removal in Primary Teeth
}

\author{
Vamsi K Reddy ${ }^{1}$, Priya Nagar ${ }^{2}$, Swetha Reddy ${ }^{3}$, Rajesh Ragulakollu ${ }^{4}$, Sunny P Tirupathi ${ }^{5}$, Ramakrishna Ravi ${ }^{6}$, Usha Purumadla ${ }^{7}$
}

\begin{abstract}
Aim: The aim of the study was to evaluate and compare bromelain with papain as the chemomechanical caries removal agent in relation to their efficacy.

Materials and methods: Thirty extracted primary molars with active carious lesion extending into dentin were selected. The samples were randomly divided into groups by sectioning the samples into two halves. Group I—cavity prepared using papain gel; group II—cavity prepared using bromelain gel. Time taken for caries removal in both the groups (I and II) was recorded with the help of a stopwatch. Following caries removal, the amount of remaining demineralized dentin was measured with the help of stereomicroscope and weld check (biological image analysis) software.

Results: $t$ test is used to evaluate the significance of study parameters on continuous scale between two groups on metric parameters. The mean of residual carious dentin thickness obtained from the group II (bromelain) was $36.74 \mu \mathrm{m}$, which was much lower than that obtained from group I (papain) with a mean of $73.84 \mu \mathrm{m}$. The mean time taken in the group II (bromelain) was 335.30 seconds which was nearly equal to the mean time of group I (papain) of 352.33 seconds.

Conclusion: The amount of remaining demineralized dentin was found to be lower in bromelain group than the papain group and time taken for the carious dentin removal was almost found similar in both bromelain and papain groups. It may be concluded that bromelain was more effective in amount of caries removal than papain.

Clinical significance: Chemomechanical caries removal with the organic gels pose a great benefit as they are less invasive and has low side effects and cost-effective.

Keywords: Bromelain, Chemomechanical caries removal, Demineralized dentin, Minimal invasive dentistry, Papain, Primary teeth.

The Journal of Contemporary Dental Practice (2019): 10.5005/jp-journals-10024-2711
\end{abstract}

\section{INTRODUCTION}

In children with dental anxiety, caries removal by means of traditional instruments, such as airotor and high-speed handpiece, is often challenging. There has been a substantial interest in developing alternative minimal invasive techniques for cavity preparation and caries removal due to the disadvantages of using conventional instruments, which results in heat, pressure, vibration, dentine desiccation, and pain. ${ }^{1}$

Chemomechanical caries removal is a minimal invasive technique removing infected dentin via a chemical agent. The objective of chemomechanical substances is to eliminate the most external portion (infected layer) where collagen is degraded, leaving the affected demineralized dentin which is proficient of being remineralized and repaired. ${ }^{2}$

Chemomechanical method of caries removal was first established in 1980 based on the studies by Goldman and Kronman with the introduction of GK-101, followed by GK-101E, which was marketed as a Caridex system. Caridex system was eventually deserted because of its lack of efficiency and convenience. Later in 1998, Carisolv system was introduced in Sweden (Mediteam). Carisolv system consists of two gels: one gel contains $0.95 \%$ sodium hypochlorite and the other gel contains three amino acids such as glutamic acid, lysine and leucine, sodium chloride, carboxymethyl-cellulose, sodium hydroxide, and water. The Carisolv system was not that popularized because this system is expensive as well as it requires customized hand instruments for excavation.

A research project in Brazil in 2003 lead to the development of a new formula to universalize the use of a chemomechanical caries removal method. The new formula was commercially known as Papacarie which basically contains papain, chloramines, toludine blue, and salts and thickening
1,4,5 Department of Pedodontics and Preventive Dentistry, Malla Reddy Institute of Dental Sciences, Hyderabad, Telangana, India

${ }^{2}$ Department of Pedodontics and Preventive Dentistry, Krishnadevaraya College of Dental Sciences and Hospital, Bengaluru, Karnataka, India

3,6 Department of Conservative Dentistry and Endodontics, Malla Reddy Institute of Dental Sciences, Hyderabad, Telangana, India

${ }^{7}$ Department of Periodontics, Malla Reddy Institute of Dental Sciences, Hyderabad, Telangana, India

Corresponding Author: Sunny PTirupathi, Department of Pedodontics and Preventive Dentistry, Malla Reddy Institute of Dental Sciences, Hyderabad, Telangana, India, Phone: +91 9490549454, e-mail: dr. priyatham@gmail.com

How to cite this article: Reddy VK, Nagar P, Reddy S, et al. Bromelain vs Papain Gel for Caries Removal in Primary Teeth. J Contemp Dent Pract 2019;20(11):1345-1349.

Source of support: Nil

Conflict of interest: None

vehicle making it a bacteriostatic, bactericidal, and antiinflammatory agent. ${ }^{3}$

Bromelain is an extract derived from the stems of pineapples, although it exists in all parts of fresh plant and fruit. This bromelain has anti-inflammatory, bacteriostatic, and bactericidal properties similar to that of papain. Therefore, the aim of the study was to evaluate bromelain as the chemomechanical caries removal agent and to compare it with papain in relation to their efficacy.

\section{Materials and Methods}

The study was approved by the Ethical Committee of Krishnadevaraya College of Dental Sciences and Hospital, Bengaluru, where 30 carious 
extracted primary molars were collected from the Department of Pedodontics and Preventive Dentistry, Krishnadevaraya College of Dental Sciences, Bengaluru, Karnataka, India.

\section{Inclusion Criteria}

Primary molars with occlusal carious lesions involving dentin and which are indicated for extraction.

\section{Exclusion Criteria}

Primary molars indicated for extraction other than reasons of decay. Primary molars with carious lesions which can be restorable and which are indicated for pulp therapy.

\section{Preparation of Bromelain and Papain Gels (Figs 1 and 2)}

Papain and bromelin gels were prepared in Department of Biotechnology, Sir M. Visvesvaraya Institute of Technology, Bengaluru. Same ingredients were used for the preparation of papain and bromelain gels to prevent bias. The composition of the ingredients is listed in Table 1.

\section{Storage and Shelf Life of Bromelain and Papain Gels}

Both the gels can be stored at room temperature and they have a shelf life of 1 year.

Thirty primary molars with active carious lesion extending into dentin extracted due to normal physiological root resorption were collected and were stored in $10 \%$ formalin, ${ }^{4}$ for a period of 2 weeks according to guidelines for infection control of extracted teeth used for research and teaching given by the Centers for Disease Control and Prevention (CDC). ${ }^{5}$ Each tooth was subjected to radiographical evaluation [intra oral periapical radiograph (IOPA)] to check the extent

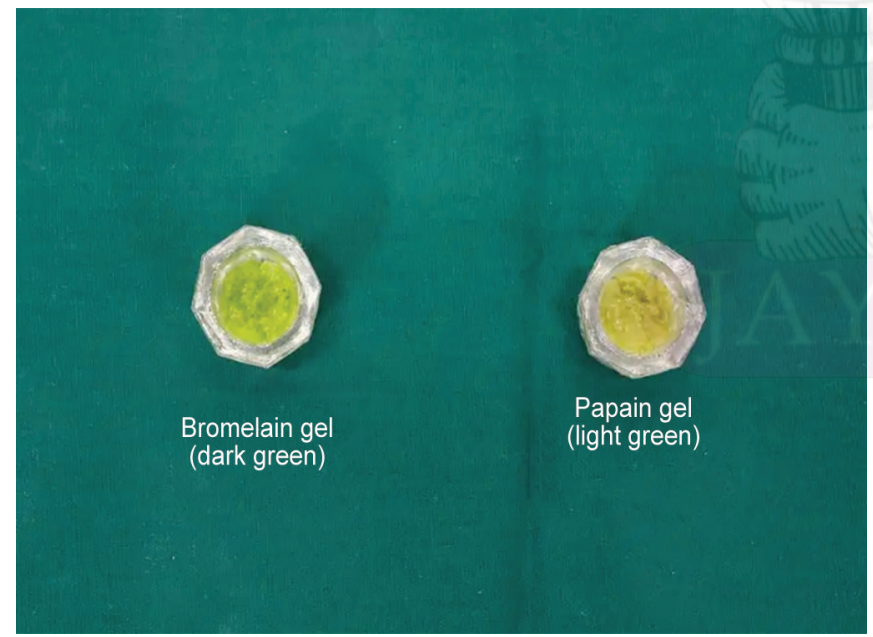

Fig. 1: Bromelain and papain gel of carious lesion. Primary teeth with active carious lesion extending to dentine without involvement of pulp were selected. ${ }^{1}$ Carious lesions on each primary molar tooth were sectioned into two halves. The sectioned halves were divided into two groups. Group I — cavity prepared using papain gel, group II-cavity prepared using bromelain gel. The teeth were decoronated at the level of cemento-enamel junction. Only the crown portion of teeth was selected, and it was further sectioned through the center of carious lesion in mesio-distal direction. ${ }^{3}$

\section{Chemomechanical Caries Removal Method (Fig. 2)}

For both papain group (group I) and bromelain group (group II), respective gels were applied and left in the cavity for 60 seconds. When the gel was cloudy, it was removed gently by scraping with the spoon excavator without applying pressure, after which additional fresh gel was applied on the excavation site and carious dentin was removed with spoon excavator. Both the gels were reapplied until it presented a light coloring, indicative of nonexistence of softened carious tissue. The gel in the cavity was flushed with water and cavity was wiped with a moistened cotton pellet. Complete carious tissue removal was confirmed using visual clinical criteria and by relying on tactile sensations. Complete caries removal was confirmed using a sharp dental explorer by passing it easily over hard sound dentin which did not catch or give a tugback sensation. ${ }^{6}$ The time taken for carious dentin excavation using papain and bromelain gels in their respective groups was recorded with stopwatch and then compared.

\section{Preparation of Specimen for Evaluation of Residual Carious Dentin (Fig. 3)}

The specimens were mounted on wax bases. The wax bases were oriented on to the stereomicroscope and the images of the

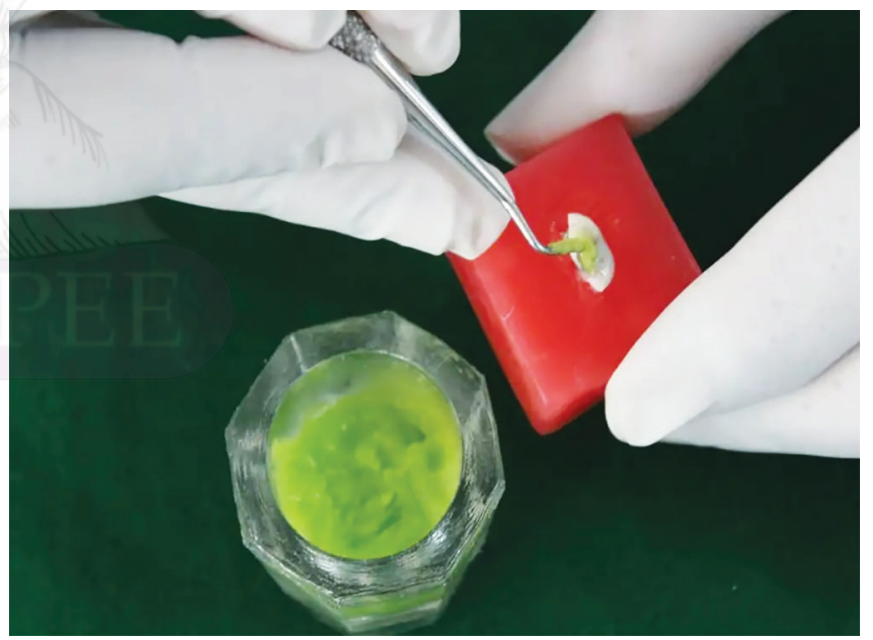

Fig. 2: Chemomechanical caries removal after gel application

Table 1: Composition of bromelain and papain gel

\begin{tabular}{llll}
\hline Papain gel & $5 \mathrm{~g}$ & Bromelain gel & $5 \mathrm{~g}$ \\
\hline Papain powder & $250 \mathrm{mg}$ & Bromelain powder & $250 \mathrm{mg}$ \\
D-a-Tocopherol acetate & $0.5 \mathrm{~mL}$ & D-a-Tocopherol acetate & $0.5 \mathrm{~mL}$ \\
Carbopol-distilled water & $200 \mathrm{mg}+2 \mathrm{~mL}$ & Carbopol-distilled water & $200 \mathrm{mg}+2 \mathrm{~mL}$ \\
Amylopectin-distilled water & $50 \mathrm{mg}+1 \mathrm{~mL}$ & Amylopectin-distilled water & $50 \mathrm{mg}+1 \mathrm{~mL}$ \\
Propyl-p-hydroxy benzoate & $100 \mathrm{mg}$ & Propyl-p-hydroxy benzoate & $100 \mathrm{mg}$ \\
Color (green apple) & & Color (green apple) & \\
Distilled water & $1 \mathrm{~mL}$ & Distilled water & $1 \mathrm{~mL}$ \\
\hline
\end{tabular}




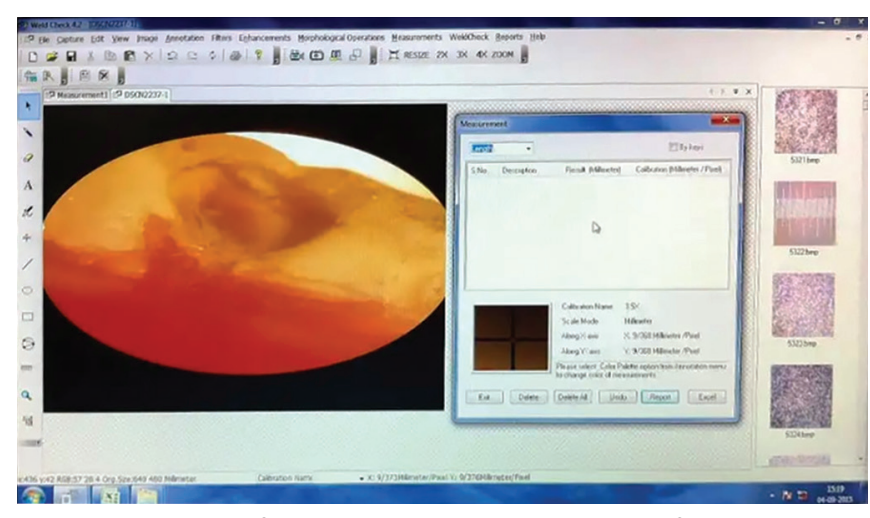

Fig. 3: Calculation of residual demineralized dentine after excavation

specimens focusing on the caries removed cavity were taken in $20 x$ magnification. For all the samples, the thickness of the remaining demineralized dentin was measured in microns using weld check software. Three values were taken at different points from the cavity floor and the average was calculated for both group I (papain) and group II (bromelain) and comparison was done between two groups. Following these, to further confirm the remaining caries present, caries-detecting dye was used to know any amount of remaining caries.

\section{Statistical Analysis}

Data were recorded in excel sheets, and statistical analysis was performed using SPSS for Windows release 19.0 (SPSS Inc., Chicago, $\mathrm{IL}$, USA). Student $t$ test has been used to find the significance of study parameters on continuous scale between two groups on metric parameters.

\section{Results}

The mean and standard deviation values for both group I and group II were calculated (Table 1). The mean time taken for caries removal in the group II (bromelain) was 335.30 seconds with standard deviation 47.72 which was nearly equal to the mean time of group I (papain) of 352.33 seconds with standard deviation 48.81. The inferential statistics using unpaired student $t$ test showed that the mean time of the bromelain group was not significant compared to the mean time of the papain group with $p$ value 0.180 .

The mean and standard deviation values of the amount of residual carious dentin for both group I and group II are summarized in Table 2. The mean of residual carious dentin thickness obtained from the group II (bromelain) was $36.74 \mu \mathrm{m}$ with standard deviation 4.25 which was much lower than that obtained from group I (papain) with mean $73.84 \mu \mathrm{m}$ and standard deviation 5.03. The inferential statistics using unpaired student $t$ test showed that the mean of remaining demineralized dentin thickness obtained from the group II (bromelain) was found to be very highly significant compared to that of group I (papain) with $p$ value $<0.05$.

\section{Discussion}

Anxiety and fear are one of the main barriers which hamper the receptivity of dental treatment. The traditional drill and fill techniques can provoke anxiety, discomfort, and fear especially among children. ${ }^{7}$ In children, it is difficult to differentiate between fear- and anxiety-derived behavior problems. ${ }^{8}$ The chemomechanical caries removal method was developed to overcome these obstacles and to preserve as much dentin as possible. This method uses substance that softens pre-degraded collagen of the carious lesion and promotes its easy removal. Chemomechanical caries removal does not affect the adjoining healthy tissues and avoids pain stimuli. Chemomechanical caries removal can be used safely and efficiently in treating special healthcare needs patient. ${ }^{9}$ Papain and bromelain gels: the gels used in this study are natural products consisting of enzymes, papain, and bromelain which are extracted from raw papaya fruit and pineapple fruit/tree, respectively.

Papain is an enzyme similar to human pepsin. It has proteolytic, anti-inflammatory, anti-bacterial, and has whitening properties. ${ }^{10}$ Papain acts only on mutilated tissue due to the absence of the antiplasmatic protease and a-1-antitripsine, which inhibits its proteolytic action on normal tissues. ${ }^{11}$ Guzman and Guzman performed clinical studies on patients with skin lesions caused by burns, perceiving that the enzymatic action of papain was considered excellent in areas with necrotic and purulent processes. ${ }^{12}$

Bromelain contains a complex mixture of different thiolendopeptidases and other partially characterized components such as glucosidases, peroxidases, phosphates, glycoproteins, cellulases, and carbohydrates. It is made up of 212 amino acids and the molecular weight is $33 \mathrm{kDa} \cdot{ }^{13,14}$ Bromelain is stable at $\mathrm{pH}$ 3.0-6.5 and once it has combined with its substrate, the activity is no longer susceptible to the effect of the $\mathrm{pH}$. Bromelain also contains sulfhydryl group which is responsible for its proteolytic action. Bromelain when applied topically as a cream (35\% bromelain in a lipid base) can be beneficial in the elimination of burn debris and in acceleration of healing. A nonproteolytic component of bromelain is responsible for this effect. This component, referred to as escharase, has no hydrolytic enzyme activity against normal protein substrates or various glycosaminoglycan substrates. ${ }^{15}$ Collagenase gets activated by bromelain in living tissue which acts on denatured collagen in the eschar. This produces a demarcation between living and dead tissue. ${ }^{16}$ Bromelain has been broadly used in food industry; for meat tenderization, protein hydrolysate production and as active element to provide gentle peeling effects in cosmetic industries. ${ }^{17}$ In textile industries, bromelain is used for decomposing or partially solubilizing protein fiber from silk and wool. ${ }^{18}$ The use of bromelain as hydrolyzing agent for the release of antimicrobial peptides of leather jacket's insoluble proteins had been reported. ${ }^{19}$ Bromelain has very low toxicity, with an LD50 greater than $10 \mathrm{~g} / \mathrm{kg}$. Toxicity tests on dogs, with increasing levels of bromelain up to 750 $\mathrm{mg} / \mathrm{kg}$ administered daily, showed no toxic effects after 6 months. Dosages of $1.5 \mathrm{~g} / \mathrm{kg} /$ day administered to rats show no carcinogenic or teratogenic effects. ${ }^{20}$ In human clinical tests, side effects have

Table 2: Intergroup comparison of time for caries removal

\begin{tabular}{lllllll}
\hline Average & & \multicolumn{5}{c}{ Mean } \\
difference & tvalue & pvalue \\
\hline Papain (group I) & 30 & $230-440$ & $352.33 \pm 48.81$ & 17.03 & 1.358 & 0.180 \\
Bromelain (group II) & 30 & $191-420$ & $335.30 \pm 47.72$ & & & \\
\hline
\end{tabular}


Table 3: Intergroup comparison of remaining carious dentine

\begin{tabular}{lllllll}
\hline Average & & \multicolumn{5}{c}{ Mean } \\
difference & t value & $p$ value \\
\hline Papain (group I) & 30 & $65.66-83.33$ & $73.84 \pm 5.03$ & 37.10 & 30.89 & $<0.001^{* *}$ \\
Bromelain (group II) & 30 & $30.33-43.66$ & $36.74 \pm 4.25$ & & & \\
\hline
\end{tabular}

not been observed. Bromelain supplementation up to $460 \mathrm{mg}$ has been shown to have no effect on heart rate or blood pressure. ${ }^{21}$ In both the gels, an anti-oxidant, D-a-tocopherol acetate, was added to reduce the oxidative stress produced by the bacteria. In addition, a humectant (glycerine), an emulsifier (amylopectin), a thickener (carbopol), and a coloring agent (green apple) were included. Propyl $p$-hydroxybenzoate, a natural material found in many plants, was used as a preservative and distilled water was used as a vehicle. ${ }^{22}$

\section{Time Taken for Caries Removal}

In the present study, the mean time taken to remove carious dentin in group I was 352.33 seconds (Table 2) which was similar to the study reported by Jawa et al. (340 seconds) and Divya et al. (359.60 seconds) which were done by Papacarie caries removing agent, containing papain as the main ingredient. ${ }^{23,24}$ The experimental group, i.e., group II where bromelain gel was used also showed similar results of mean time 335.30 seconds (Table 2). There were no previous studies reported in relation to the time taken for caries removal with bromelain enzyme. In the present study, the difference in time taken for caries removal in both the groups was not statistically significant with almost similar timings.

\section{Amount of Remaining Demineralized Dentin}

In the present study, the mean remaining demineralized dentin thickness obtained from the group I was $73.84 \mu \mathrm{m}$ which was much higher than the mean value of group II of $36.74 \mu \mathrm{m}$ (Table 3). There were no studies reported in relation to the amount of residual carious dentin for papain and bromelain. In the present study, the difference of mean residual carious dentin thickness of groups I and II was statistically significant with group II having less amount of residual carious dentine. This shows that bromelain was more effective in removing the residual carious dentin than papain. This may be due the fact that papain is not very effective against collagen whereas bromelain has a much stronger action and is effective in degrading myofibrillar proteins, as suggested by Tucker et al. ${ }^{25}$

\section{Limitations}

The main limitation of this chemomechanical caries removal agents was that time involved in removing carious dentine was more when compared to traditional high-speed handpiece.

\section{Conclusion}

- The amount of residual carious dentin was found to be lower in bromelain group than the papain group and the difference was found to be statistically significant.

- The time taken for the carious dentin removal was almost found similar in both bromelain and papain groups with no statistically significant difference.

- Within the limits of this study, it may be concluded that bromelain was more effective in amount of caries removal than papain.

\section{Clinical Significance}

Bromelain and papain gels can act as a potential, safe, and economical alternative to available expensive chemo-mechanical caries removal agents in fearful children. Chemo-mechanical removal of caries with Bromelain and papain gels requires minimal instrumentation and can be of great advantage in outreach programs.

\section{Author Contributions}

Manuscript was prepared based on collaborative work of all the participating authors.

\section{References}

1. Qasim AS, Suliman AA. Evaluation of chemomechanical caries removal using the Vickers hardness test: an in vitro study. International Dentistry; 2007. pp. 34-45.

2. Al-Rawi BA. Evaluation of chemomechanical caries removal (Carisolv ${ }^{\mathrm{TM}}$ gel) on primary teeth: a microhardness study. Al-Rafidian Dent J 2012;12:289-294.

3. Ramamoorthi S, Nivedhitha M, Vanajassum P. Effect of two different chemomechanical caries removal agents on dentin microhardness. an in vitro study. J Conserv Dent 2013;16(5):429-433. DOI: 10.4103/09720707.117520

4. Lee JJ, Nettey-Marbell A, Cook Jr A, et al. Using extracted teeth for research: the effect of storage medium and sterilization on dentin bond strengths. J Am Dent Assoc 2007;138(12):1599-1603. DOI: 10.14219/jada.archive.2007.0110.

5. Kohn WG, Collins AS, Cleveland JL, et al. Guidelines for infection control in dental healthcare settings-2003. MMWR Recomm Rep 2003;52(RR-17):1-61.

6. Peters MC, Flamenbaum MH, Eboda NN, et al. Chemomechanical caries removal in children: efficacy and efficiency. J Am Dent Assoc 2006;137(12):1658-1666. DOI: 10.14219/jada.archive.2006.0111.

7. Stewart JE, Marcus M, Christenson PD, et al. Comprehensive treatment among dental school patients with high and low anxiety. J Dent Educ 1994;58(9):697-700.

8. Kuscu OO, Akyuz S. Children's preferences concerning the physical appearance of dental injectors. J Dent Child 2006;73(2):116-121.

9. Ganesh M, Parikh D. Chemomechanical caries removal (CMCR) agents: review and clinical application in primary teeth. J Dent Oral Hygiene 2011;3:34-35.

10. Bussadori SK, Guedes CC, Hermida Bruno ML, et al. Chemomechanical removal of caries in an adolescent patient using papain gel: case report. J Clin Pediatr Dent 2008;32(3):177-180. DOI: 10.17796/ jcpd.32.3.1168770338617085.

11. Flindt $M$. Health and safety aspects of working with enzymes. Process Biochem 1979;13:3-7.

12. Guzman AV, Guzman MG. The enzymatic debridement of suppurations, necrotic lesions and burns with papain. J Int Coll Surg 1953;20(6):695-702.

13. Heinicke RM, Gortner WA. Stem bromelain-a new protease preparation from pineapple plants. Econ Bot 1957;11:225-234. DOI: 10.1007/BF02860437.

14. Murachi T, Neuratii $H$. Fractionation and specificity studies on stem bromelain. J Biol Chem 1960;235:99-107. 
15. Houck JC, Chang CM, Klein G. Isolation of an effective debriding agent from the stems of pineapple plants. Int J Tissue React 1983;5(2): 125-134.

16. Kelly GS. Bromelain: a literature review and discussion of its therapeutic applications. Alt Med Rev 1996;1:243-257.

17. Aehle W. Enzymes in industry: production and applications, 3rd ed., Weinheim: Wiley: VCH/Verlag GmbH \& Co; 2007.

18. Koh J, Kang SM, Kim SJ, et al. Effect of pineapple protease on the characteristics of protein fibers. Fiber Polym 2006;7:180-185. DOI: 10.1007/BF02908264.

19. Salampessy J, Phillips M, Seneweera S, et al. Release of antimicrobial peptides through bromelain hydrolysis of leatherjacket insoluble proteins. Food Chem 2010;120:556-560. DOI: 10.1016/ j.foodchem.2009.10.054.

20. Taussig SJ, Yokoyama MM, Chinen N, et al. Bromelain: a proteolytic enzyme and its clinical application. Hiroshima J Med Sci 1975; 24(2-3):185-193.
21. Gutfreund A, Taussig S, Morris A. Effect of oral bromelain on blood pressure and heart rate of hypertensive patients. Hawaii Med J 1978;37(5):143-146.

22. Subramaniam $P$, Gilhotra K. Antimicrobial efficacy of an indigenously prepared caries removing gel. Contemp Clin Dent 2011;2(1):13-16. DOI: 10.4103/0976-237X.79294.

23. Jawa $D$, Singh $S$, Somani $R$, et al. Comparative evaluation of the efficacy of chemomechanical caries removal agent (Papacarie) and conventional method of caries removal: an in vitro study. J Indian Soc Pedod Prev Dent 2010;28(2):73-77. DOI: 10.4103/0970-4388. 66739.

24. Divya G, Prasad MG, Vasa AAK, et al. Evaluation of the efficacy of caries removal using polymer Bur, Papacarie, Carisolv, Stainless Steel Bur: an in vitro comparative study. J Clin Diagn Res 2015;9(7): ZC42-ZC46. DOI: 10.7860/JCDR/2015/12705.6202.

25. Tucker GA, Wood LFJ. Enzymes in food processing. 1st ed.; 1995. 